\title{
Assessment of Aesthetic Quality of Forest Areas Using Aerial Photograph Image Data
}

\author{
Surová, D. ${ }^{* 1 * 2}$ Surový, P. ${ }^{* 1} \&$ Yoshimoto, A. ${ }^{* 1}$ \\ Keywords: forest aesthetic quality, infra red aerial photographs, holm oak mon- \\ tado, Q. ilex subsp. rotundifolia \\ Abstract: This study proposes a new approach to assess the aesthetic quality \\ of forest areas using false color infrared aerial photographs and im- \\ age analysis techniques. The proposed approach is applied to open \\ evergreen woodlands in Portugal, which are dominated by Q. ilex \\ subsp. rotundifolia. Aesthetic quality is assessed using the follow- \\ ing indicators: spatial pattern, crown condition, percent crown cover, \\ and a tree mortality index. Results suggest a number of these indica- \\ tors, including spatial patterns, crown conditions, and percent crown \\ cover, can quickly and efficiently be assessed using readily available \\ aerial photography databases. The proposed method is especially \\ useful for large-scale field surveys that may precede more detailed \\ field assessments of specific areas.
}

\footnotetext{
Received November 26, 2012; Accepted January 15, 2013

*1 Institute of Statistical Mathematics, Japan

*2 ICAAM - Instituto de Ciências Agrárias e Ambientais Mediterrânicas, Universidade de Évora, Portugal
} 


\section{Introduction}

Maintaining non-market outputs from a forest landscape, such as biodiversity, water quality, soil retention, and aesthetic values, is becoming as important as producing timber for economic purposes. Scientists, policymakers, and citizens at large increasingly recognize the importance of non-timber outputs from forest ecosystems. Aesthetics play an increasingly prominent role in this conversation, especially as society places greater value on recreational activities in forested landscapes.

A forest aesthetic quality assessment, or forest landscape quality assessment, is a complex process that considers visual, cultural, and social factors. Evaluation can be complicated by the interrelated nature of these indicators. For example, changes in traditional forest management practices (a cultural factor) can also impact the appearance (visual aspect) of a forest landscape. Surveying public preference is one way of assessing forest or landscape aesthetic quality. There are a variety of terms used in the literature to describe the social orientation to landscape aesthetics, including "aesthetic response to landscape" (Herzog, 1984); "rating of scenic beauty" (Arthur, 1977); "visual landscape perception" (Jacobsen, 2007); "perception of scenic quality" (Ribe and Matteson, 2002); and "landscape preferences" (Tveit, 2009).

Bourassa (1991) suggests landscape preferences are in part determined by genetics and further affected by cultural orientation and personal experience. Due to our common evolutionary history, there may exist a common set of landscape features that are preferred across cultures and personal preferences. That is, even if cultural and personal differences impact landscape preferences, it may still be possible to identify some commonalities. Most landscape aesthetic quality assessments use indicators principally based on visual aspects of the landscape (Tveit et al., 2006). A review of the landscape aesthetic literature identified nine key concepts (a full review can be found in Tveit et 
al., 2006), which can be viewed as commonalities that may transcend cultural and personal differences. It is possible to derive relevant indicators for a specific landscape from these key concepts, recognizing that they vary depending on the landscape type (Tveit et al., 2006). Although there are characteristics common to all landscapes, particular forests may have unique features associated with aesthetic appreciation. Ode et al. (2008) extended the work completed by Tveit et al. (2006), introducing steps for developing measurable visual indicators. They suggest these indicators should be selected according to a clear theoretical framework, that they should be quantifiable, mappable, and relevant to the context, and that data should be available to measure them. Some of these indicators are interrelated, while others may be independent.

Mapping the aesthetic quality of forests provides a means to capture social values in much the same way economic values, such as stand density or volume, may be measured (Brown, 2005). Aesthetic quality maps can also be used to identify hot spots where restoration or preservation needs may warrant special attention from land managers (Alessa et al., 2008). Such maps are also integral to management plans, which must increasingly consider social values (Reed and Brown, 2003). To efficiently create these maps - to assign different levels of aesthetic value to forests over space - we need a tool and a methodology for spatial aesthetic quality assessment that is consistent with common preferences for a given forest landscape.

In this paper, we define aesthetic quality as the value of the visual and cultural aspects of a forest stand. We consider two layers of mappable indicators. The first is represented by indicators that can be directly observed and are derived from a) general concepts for assessment of aesthetic quality, and b) regionally-specific visual and cultural factors. The second layer contains a tree mortality index derived from 
infrared aerial photographs. Tree mortality is often difficult to observe directly in the field, but will eventually become visible and influence the aesthetic value of a stand.

In this paper we propose a new approach to assess the aesthetic quality of forest areas using false color infrared aerial photographs and image analysis techniques. The resulting maps are an accessible and affordable data source available to land managers and the research community. The proposed approach includes a) identification of relevant indicators for forest aesthetic quality, and b) development of a methodology to apply the indicators to an assessment of aerial photographs.

\section{Methods}

The methodological framework requires a) identification of appropriate aesthetic quality indicators for a specific forest, and b) the appropriate application of image processing techniques to aerial photographs. Aesthetic quality indicators were identified from general knowledge about landscape aesthetics, research from regional studies about landscape preferences, and studies on the aesthetic impacts of various forest management regimes. These indicators were then used to assess false color infrared aerial photographs using image processing techniques and expert evaluation.

\subsection{Study Area}

The study was conducted in holm oak (Quercus Ilex subsp. rotundifolia Lam.) forest stands near Évora in Southern Portugal. The analysis was performed in those areas covered by both pure and mixed holm oak forest stands. Holm oak is a drought tolerant, medium-size tree that grows $20-27 \mathrm{~m}$ tall with finely square-fissured blackish bark and leathery evergreen leaves. Average stand density and tree crown cover is about 30 trees per ha and $21 \%$, respectively (Carreiras et al., 
2006). The understory consists of herbaceous annuals and legumes invaded by shrubs, mainly Cistus salviifolius L. The climate in the area is Mediterranean, with hot, dry summers and moderate, rainy winters (Lionello, 2012). The soil has a maximum depth of about $1 \mathrm{~m}$, overlying granite bedrock, and displays generally low water retention capacity.

Holm oak forests are dominant on the Iberian Peninsula, as well as within the Mediterranean basin as a whole. They are managed primarily for the production of acorns to feed livestock and for fuelwood. Natural regeneration of holm oak forests has been severely impacted by human transformation. Today, holm oak forests cover 20,000-30,000 $\mathrm{km}^{2}$ on the Iberian Peninsula, whereas without human development holm oak could potentially cover as much as $300,000 \mathrm{~km}^{2}$. Most of today's holm oak forests and woodlands are disturbed and fragmented into small islands and mosaics (Blanco et al., 1997).

Holm oak is mainly concentrated in the drier, eastern inland regions of Portugal, as opposed to Cork oak (Quercus suber L.), which is concentrated more in the western part of the country influenced by an oceanic climate. In the lowlands of Central Spain and of Southern Portugal a distinct kind of land management led to the transformation of dense natural forests into extensive "park-like" landscapes. These parklike areas, called "montado" in Portugal and "dehesas" in Spain, are distinguished in terms of their systematic combination of agricultural, pastoral, and forestry uses. The cork oak and holm oak are dominant tree species in the montado.

The montado have been identified by European Union directive 92/43 as a natural habitat type of worldwide significance for the conservation of globally endangered species. Moreover, maintaining the montado is important for the preservation of natural resources, including soil and water, the regional production of corn and livestock, and for its amenity values. 


\subsection{Basis for the Indicators}

\subsubsection{General Concepts for Assessment of Landscape Aesthet-} ics

Six of the original nine concepts for landscape visual quality assessment (Ode et al., 2008) are applicable to aerial assessment of forest stands. Those six include complexity, coherence, stewardship, visual scale, naturalness, and disturbance.

1) The concept of complexity relates to the diversity and richness of forest elements or patterns. Indicators of complexity include the number of different forest attributes, their spatial uniqueness, and variability across the landscape.

2) The concept of coherence focuses principally on the presence of water and spatial arrangement of vegetation. Coherence also includes colors and textures across the landscape.

3) The concept of stewardship refers to the type and degree of active management, and its impact on aesthetic characteristics of a forest stand. Principle indicators mentioned in the literature include the type of management activities and current successional stage of a stand. Crown condition is an important factor - full foliage of holm oaks has no apparent crown transparency when observed on aerial photographs. High crown transparency is considered to have a negative visual impact, reflecting intensive pruning or loss of foliage due to disturbance.

4) The concept of visual scale principally describes the degree of openness in the landscape. Indicators include the percent of open land, size and shape of the viewshed, and density of obstructing objects.

5 ) The concept of naturalness includes the percent of natural vegetation, the physical shape of vegetation, the current successional stage, the percent of water, and the fractal and fragmentation indices.

6) The concept of disturbance refers to a lack of coherence. Indi- 
cators include forest attributes generally associated with known types of disturbance, as well as clear visual signs of disturbance. To apply these indicators, it is important to identify which forest elements or characteristics are perceived as disturbance in a specific place.

The indicators for these six concepts are interrelated, such that changes to a forest landscape may impact more than one concept at the same time. Likewise, two or more concepts may have similar or identical indicators.

Three additional concepts for landscape visual quality assessment were not considered because their specific characteristics exceed the scope of our stand-level analysis. These include historicity, imageability, and ephemera.

7) The concept of historicity refers to the degree of historical richness present in a forest. The holm oak montado is a traditional land use system that has been in place for centuries and thus has significant historical value.

8) The concept of imageability is the product of the total coordination of the landscape or its spatial elements. That is, it is the overall uniqueness of the landscape such that it is distinguishable from other landscapes and memorable to the observer. Most of the indicators related to spectacular, unique, and iconic elements cannot be estimated using aerial photographs or land cover data - they require direct observation - though it may be possible to determine some indicators, such as the density of potential viewpoints.

9) The concept of ephemera reflects landscape changes related to season or weather. Ephemera can be measured by percent of area with seasonal changing forests (e.g., broadleaf forests) and percent of water with seasonal change. 


\subsubsection{Regional Concepts - Landscape Preferences and Man- agement Transitions}

Regional information was taken from studies about landscape preferences (Surová and Pinto-Correia, 2008) and principal management transitions (Pinto-Correia, 1993) in the studied forest. These two previous studies include overlapping visual and cultural information about the montado.

\section{Landscape Preferences}

The 2008 landscape preference study (Surová and Pinto-Correia) showed that montado users preferred an irregular spatial pattern of tree placement, as opposed to stands of regularly aligned trees. Irregular tree placement increases complexity and is perceived to reflect more natural conditions, thereby increasing the degree of coherence. The most preferred montado type had 10-60\% crown cover.

The assessment also revealed users prefer full crown foliage. Respondents suggested dense foliage created refreshing spaces and aesthetically pleasing light contrasts. The presence of livestock was also highly preferred by forest users.

\section{Management Transitions}

The 1993 study by Pinto-Correia highlights the visual consequences of various management decisions in the montado. Intensification was linked to reductions in tree density (10-20 trees per ha) and in increased quantity of grazing animals. On the other side, extensification was linked to dense stands with scrub with subsequent declined tree management. In some areas both intensification and extensification can be observed. The result is a mixed landscape with dense, inaccessible stands adjacent to open, low density areas. Changes in management patterns are causing a loss of traditional dispersed park-like spatial arrangements, resulting in the appearance of diminished coherence and 
stewardship - an overall decrease in aesthetic quality.

\subsubsection{Tree Mortality Index}

Tree mortality is a serious concern in most of Portugal's oak forests (Ribeiro and Surový, 2008). In this study we used the mortality index as an indicator of disturbance, identifying three levels of mortality based on the density of dead trees in a given stand. This indicator was mapped on a separate layer using infrared aerial photographs (tree mortality is frequently undetectable on RGB images).

In summary, we defined five relevant and mappable indicators of aesthetic quality in the study area. These include two indicators for spatial tree patterns, indicators of crown condition and cover, and a tree mortality index. Table 1 shows the relation between general and regional concepts considered in this study and the associated indicators. Note that some general concepts are interrelated and have common indicators, while others (i.e., coherence and landscape preferences) have several mappable indicators.

Table 1. Relation between general and regional concepts considered in the study and the resultant indicators.

\begin{tabular}{|c|c|c|c|}
\hline General concepts & Regional concepts & Indicators & \\
\hline coherence; stewardship & management transitions & $\begin{array}{l}\text { spatial pattern of trees } \\
\text { (dispersed vs agregated) }\end{array}$ & A1 \\
\hline $\begin{array}{l}\text { coherence; complexity } \\
\text { and naturalness }\end{array}$ & landscape preferences & $\begin{array}{l}\text { spatial pattern of trees } \\
\text { (irregular vs aligned) }\end{array}$ & $\mathrm{A} 2$ \\
\hline disturbance & landscape preferences & crowns' condition & B \\
\hline visual scale & landscape preferences & percentage of crown cover & C \\
\hline disturbance & & trees mortality index & $\mathrm{D}$ \\
\hline
\end{tabular}




\subsection{Image Analysis and Variable Assessment}

The national land cover map of Portugal (COS, 2007) was used to identify areas with pure or mixed holm oak stands. We used previously established methodology for automatic crown cover detection (Surový et al., 2004) and identification of tree mortality (mortality index) (Ribeiro and Surový, 2008). Crown cover was obtained through automatic segmentation so that the total number of pixels belonging to tree crowns divided by the total number of pixels in a given polygon represents crown cover. The mortality index was calculated as the number of dead trees per hectare, weighted negatively by the crown cover. The higher the crowns cover and lower the number of dead trees, the higher the mortality index.

\subsection{Qualitative and Quantitative Approaches to Visual Qual- ity Assessment}

The analysis resulted in two separate layers of information. The first layer contained values related to observable indicators; the second had values from the tree mortality index. The final value of overall stand aesthetic quality is derived from these two values. The first layer value results from the assessment of four indicators (Table 2)-spatial tree pattern (indicators A1 and A2), crown condition (indicator $\mathrm{B})$, and percent crown cover (C). These were evaluated for each forest stand (polygon). Indicator A1 is considered satisfied when the majority of crowns $(>50 \%)$ are spatially dispersed across the polygon. In this case, the indicator receives one point. Otherwise, when the majority of crowns overlaps and/or is adjacent to an open area with few trees, the polygon receives no points. The second indicator reflects the spatial pattern of trees (A2) by distinguishing irregular and aligned tree composition. Polygons where a majority of crowns $(>50 \%)$ are distributed irregularly are evaluated positively and receive one point. When a ma- 
jority of crowns $(>50 \%)$ are distributed regularly, the polygon receives no points.

Table 2. Description of aesthetic quality indicators for holm oak stands and the type of analysis applied to aerial images.

\begin{tabular}{llll}
\hline Indicators & Highest value: 1 & Lowest value: 0 & $\begin{array}{l}\text { Type of analysis } \\
\text { applied on aerial } \\
\text { images }\end{array}$ \\
\hline A1 spatial pattern of trees & dispersed & aggregated & \\
A2 spatial pattern of trees & irregular & aligned & expert visual \\
& & & analysis \\
B crowns' condition & no transparency & transparency & \\
C percentage of crown cover traditional (10-60\%) & other $(<10 \%$ or $>60 \%)$ & computer analysis \\
D trees mortality index & $<$ regional average & $>$ regional average & combined analysis \\
\hline
\end{tabular}

The crown condition indicator (B) represents crown visual transparency. One point is assigned when the majority $(>50 \%)$ of crowns in a stand have no visual transparency on aerial photographs. The percentage of crown cover (indicator C) is calculated for each polygon automatically using previously developed software for automatic crown cover segmentation (Surový et al., 2004). The highest value on the visual scale indicator (one point) is attributed to stands with 10-60\% crown cover; otherwise, the polygon receives no points.

Based on evaluation of indicators A1, A2, B, and C, each polygon receives an ordinal scaled value from 1 to 3 . If none or only one indicator is applicable, one point is assigned to the forest stand. When two or three indicators are applicable, the stand receives two points. When all four indicators are applicable, the stand receives three points.

The second layer contains information from the mortality index. This quantitative evaluation is completed through automatic scaling for tree mortality on forest stands at the individual tree level. The mortality scale is classified into three levels (1-low, 2-normal, 3-high) using 
an automatic (unsupervised) classification technique (ArcGis-Natural Breaks, Jenks). Examples of stands with different values of visual quality are shown in Photos 1-3.

The final value assigned to describe a stand's aesthetic quality is derived from overlapping the two information layers (Table 3).

Table 3. Final aesthetic quality values for holm oak montado stands.

\begin{tabular}{cccc}
\hline & Layer 1 & Layer 2 & Final Layer \\
\hline $\begin{array}{c}\text { Observable } \\
\text { indicators }\end{array}$ & $\begin{array}{c}\text { Tree } \\
\text { Mortality Index }\end{array}$ & $\begin{array}{c}\text { Aesthetic quality of } \\
\text { forest stand }\end{array}$ \\
\hline indicators & A1,A2, B and C & D & A1, A2, B, C and D \\
\hline \multirow{5}{*}{ values } & 1 & 1 & 1 \\
& 1 & 2 & 2 \\
& 1 & 3 & 3 \\
& 2 & 1 & 4 \\
& 2 & 2 & 5 \\
& 3 & 3 & 6 \\
& 3 & 1 & 7 \\
& 3 & 2 & 9 \\
\hline
\end{tabular}

Value of observable indicators: 1 - zero or one indicator reach highest value for the stand; 2 - two or three indicators reach highest value for the stand; 3 - all four indicators reach highest value.

Value of tree mortality index: 1 - low; 2 - normal; 3 - high. Indicators: A1 - spatial pattern of trees (dispersed vs. aggregated); A2 - spatial pattern of trees (irregular vs. aligned); B - crown conditions (no transparency vs. transparency); C - percent crown cover; D - mortality index. 


\section{Results}

\section{Relevant Indicators of Aesthetic Quality}

Table 2 describes the indicators used to assess the aesthetic quality of holm oak stands and the type of analysis applied to aerial images. The highest visual quality value was attributed to holm oak stands with irregular spatial distribution, crowns with no or low transparency, and crown cover values of $10-60 \%$.

The final aesthetic quality value is derived from overlapping the informational layer of observable indicators with the mortality index layer (Table 3).

\section{Results from Application of Proposed Methodology to Aerial Photographs}

Applying the proposed methodology resulted in clear distinction of montado polygons based on observable differences between stands (Photos 1-3). In the case of Photo 1, only indicator A2 reached the highest value and the tree mortality index was above the regional average. In Photo 2, indicators $\mathrm{A} 2$ and $\mathrm{C}$ reached the highest value, while the tree mortality index equaled the regional average. The example shown in Photo 2 represents a heterogeneous montado polygon where some areas have a higher than ideal percentage of land cover (likely from abandonment of understory management), while others are more open (likely from grazing pressure). The average crown cover of this polygon (indicator C) approximates ideal values; however, the aggregated spatial distribution of trees (indicator A) and crowns with signs of transparency (indicator $\mathrm{C}$ ) do not correspond to the highest aesthetic value. Finally, in Photo 3, all four indicators (A1, A2, B and C) reached the highest value and the tree mortality index was lower than the regional average. These three cases clearly demonstrate that the chosen indicators can be used to differentiate visual stand quality. 


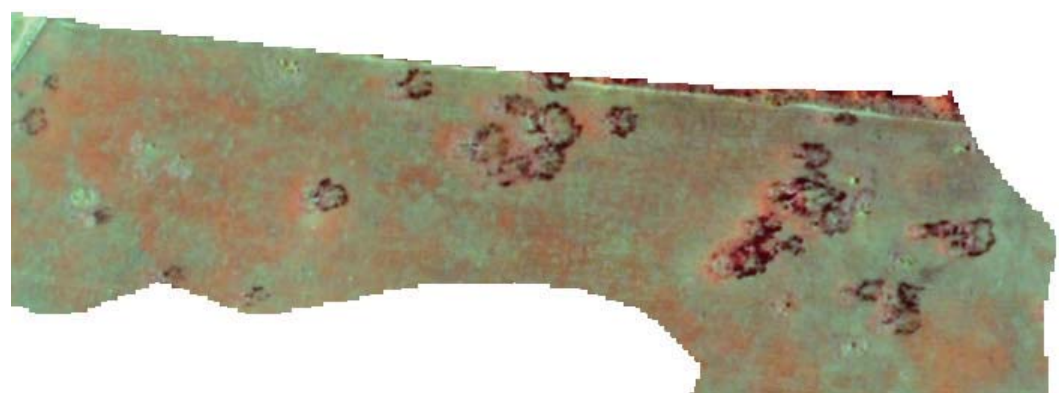

Photo 1. Example of stand aesthetic quality 1.

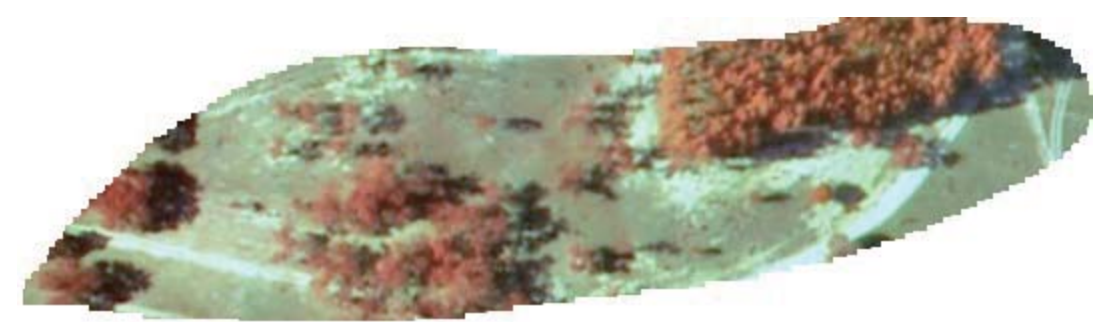

Photo 2. Example of stand aesthetic quality 5.

Figure 1 shows part of an output map from application of the proposed method to holm oak stands in Southern Portugal. Different shades of gray correspond to different stand aesthetic quality levels. The darker the color, the higher the aesthetic quality value.

\section{Conclusions}

Aesthetic landscape qualities are an increasingly important consideration for land managers and policymakers who should make forest management decisions that reflect social values. Thus, it is necessary to obtain or develop high quality databases to help inform these decisions. The approach proposed here demonstrated that several forest aesthetic quality indicators can be assessed by aerial photographs, en- 


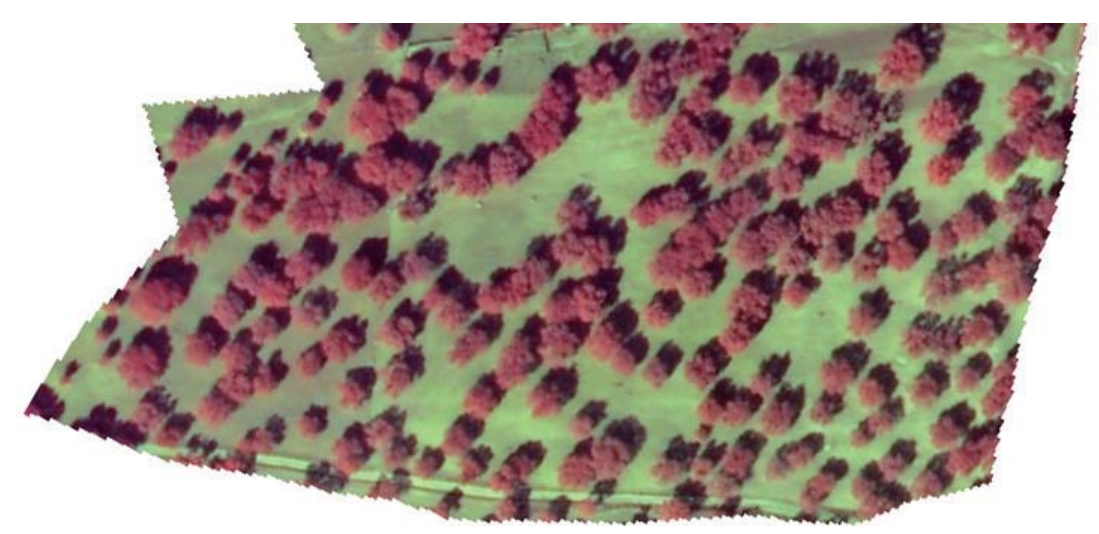

Photo 3. Example of stand aesthetic quality 9.

abling cost-effective and time-efficient development of such databases. Our methodology was based on five indicators - two indicators of spatial tree patterns, an indicator of crown condition, percent crown cover, and an index of tree mortality. We tested this methodology on open evergreen holm oak montado forests in Southern Portugal.

As observed in previous studies about landscape aesthetics (e.g., Purcell and Lamb, 1998), some concepts were interrelated. In the case of holm oak montado, the spatial pattern of tree distribution had greatest impact on coherence, stewardship, complexity, and naturalness. When applied to other forest areas, though, regional context must be considered. Forest types, as well as specific social values related to place, are important in defining those aesthetic indicators that are connected with regional traditions and cultural values.

The principle output from the proposed approach is a visual (map) representation of the spatial distribution of stands with specific aesthetic quality values. This kind of information can help inform more effective spatial forest management. It can also facilitate communication between decision makers and stakeholder groups with diverse 


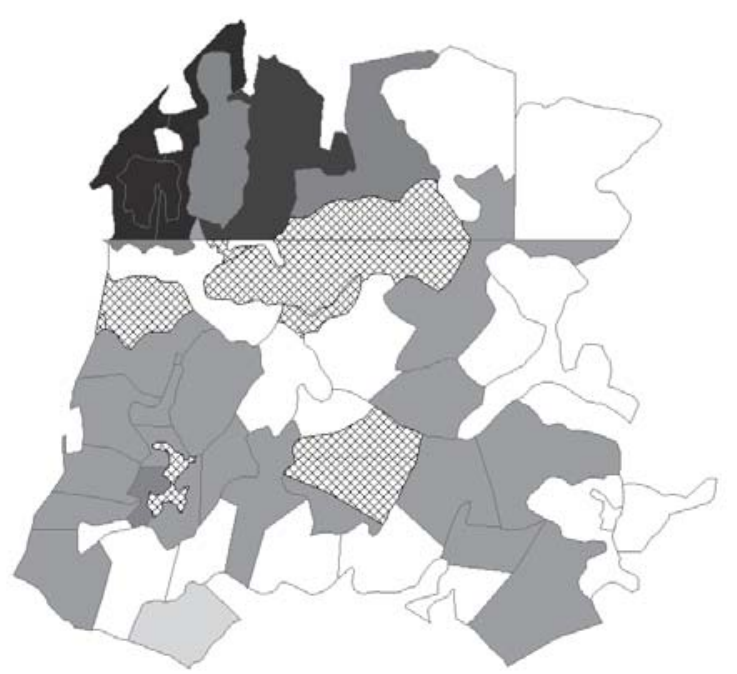

Figure 1. Example of an output map from application of the proposed method to holm oak stands in Southern Portugal.

interests regarding the real and perceived relative tradeoffs among various management options for ecosystem services and their locations.

In terms of resources needed for evaluation, the proposed method is less time-consuming and more cost-effective than direct field observation. Application of the proposed method does not involve field visits. It simply requires aerial images from the study area and one or more technicians to conduct the image analysis. Analysis through aerial images requires on average two hours per square kilometer. Travel time not withstanding, field evaluation requires on average 6 hours per square kilometer.

Field evaluation may be necessary in cases where other indicators of aesthetic quality must be evaluated. Some indicators, such as the condition of man-made structures like fences and buildings, can only be evaluated through field visits or landscape photographs. At the same 
time, landscape level evaluation makes it possible to include landscape features such as surface water elements that are important components of complexity and imageability, or even monuments significant to the concept of historicity. Thus, the proposed methodology could be used in conjunction with field visits to evaluate a greater range of indicators. Logically, completing this kind of multiple method analysis at a regional or even national level would require additional time and resources. From this perspective, it may be advantageous to implement the proposed methodology to acquire a preliminary landscape-level survey before planning more detailed field measurements, which could be focused in areas of specific interest.

\section{Acknowledgements}

Financial support from FEDER Funds through the Operational Programme for Competitiveness Factors - COMPETE and National Funds through FCT - Foundation for Science and Technology under the Strategic Project PEst-C/AGR/UI0115/2011 and post-doctoral grants for the first and second author from Japan Society for Promotion Science, is gratefully acknowledged.

\section{References}

Alessa, L., Kliskey, A. and Brown, G. (2008) Social-ecological hotspots mapping: a spatial approach for identifying coupled social-ecological space, Landscape Urban Plan. 85: 27-39.

Arthur, L. M. (1977) Predicting scenic beauty of forest environments: Some empirical tests, Forest Sci. 23: 151-159.

Blanco, E., Casado, M. A., Costa, M. R. E., García, M., Génova, M., Gómez, A., Gómez, F., Moreno, J. L., Morla, C., Regato, P. and Saínz, H. (1997) Los Bosques Ibéricos. Una Interpretación 
Geobotánica, Planeta, Madrid, p.572 (in Spanish).

Bourassa, S. C. (1991) The Aesthetics of Landscape, Belhaven Press, London and New York.

Brown, G. (2005) Mapping spatial attributes in survey research for natural resource management: methods and applications, Soc. Nat. Resour. 18: 17-39.

Carreiras, J. M. B., Pereira, J. M. C. and Pereira, J. S. (2006) Estimation of tree canopy cover in evergreen oak woodlands using remote sensing, Forest Ecol. Manage. 223: 45-53.

Chhetri, P., Arrowsmith, C. and Jackson, M. (2004) Determining hiking experiences in nature based tourist destinations, Tour. Manag. 25: $31-43$.

Herzog, T. (1984) A cognitive analysis of preference for field and forest environments, Landscape Res. 9: 10-16.

Jacobsen, J. S. K. (2007) Use of landscape perception methods in tourism studies: A review of photo-based research approaches, Tour. Geogr. 9: 234-253.

Lionello, P. (Ed.) (2012) The Climate of the Mediterranean Region, From the past to the future, Elsevier, Amsterdam, Netherlands, p.502.

Ode, A., Tveit, M. and Fry, G. (2008) Capturing landscape visual character using indicators: touching base with landscape aesthetic theory, Landscape Res. 33: 89-117.

Pinto Correia, T. (1993) Threatened Landscape in Alentejo, Portugal: the Montado and other Agro-Silvo-Pastoral Systems, Landscape Urban Plan. 24: 43-48.

Purcell, A. T. and Lamb, R. J. (1998) Preference and naturalness: an ecological approach, Landscape Urban Plan. 42: 57-66.

Ribe, R. G. and Matteson, M. Y. (2002) Views of old forestry and new among reference groups in the Pacific Northwest, West. J. Appl. 
Forestry 17: 1-10.

Ribeiro, N. A. and Surový, P. (2008) Inventário nacional de mortalidade de sobreiro na fotografia aérea digital de 2004/2006, Universidade de Évora, Évora, p.82 (in Portuguese).

Reed, P. and Brown, G. (2003) Values suitability analysis: a methodology for identifying and integrating public perceptions of ecosystem values in forest planning, J. Environ. Plan. Manag. 46: 643-658.

Surová, D. and Pinto-Correia, T. (2008) Landscape preferences in the Cork Oak Montado in the region of Alentejo, Southern Portugal: searching for valuable landscape characteristics for different user groups, Landscape Res. 33: 311-330.

Surový, P. Ribeiro, N. A., Oliveira, A. C. and Scheer, L. (2004) Detection of the vegetation from background in high resolution color remote sensed imagery, J. Forest Sci. 50: 161-170.

Tveit, M., Ode, A. and Fry, G. (2006) Key concepts in a framework for analyzing visual landscape character, Landscape Res., 31: 229-255.

Tveit, M. S. (2009) Indicators of visual scale as predictors of landscape preference; a comparison between groups, J. Environ. Manag. 90: $2882-2888$. 